\title{
Research on Evaluation of Regional Ecological Innovation Efficiency in Anhui Province
}

\author{
Zhu Dongyun \\ School of public Affairs, University of Science \& Technology of China, 230026,P.R.China. \\ Zhu Hai lun* \\ Hefei Institute for Public Safety Research, Tsinghua University, 230026,P.R.China
}

\begin{abstract}
With the development of technology, the negative effects brought about by innovation have become more and more attractive. But there are few studies on the relative efficiency of input and output in a region. Since the input and output of a region are multidimensional variables. Therefore, this paper adopts the DEA method, first analyzes 16 cities in Anhui Province without environmental pollution index, and finds that Hefei is in an inefficient region with decreasing scale. Under the same input, it is necessary to improve the efficiency of technology input. After introducing the environmental index, Hefei has reached the effective input standard, and four cities have not reached the effective decision-making unit. Among them, Maanshan, Xuancheng and Anqing are in the stage of increasing returns to scale. For these three regions, technology investment can be increased. . Based on the results of the above data analysis, the corresponding measures are proposed and the direction of policy designation is indicated.
\end{abstract}

Keywords: ecological innovation; efficiency; environmental pollution index; Anhui

DOI: $10.7176 / \mathrm{JLPG} / 87-07$

Publication date:July $31^{\text {st }} 2019$

\section{Introduction}

China has witnessed a rapid economic development since the 18th National Congress, when the five principles of development —_ "Innovation, Coordination, Green, Openness, and Sharing" had been put forward by President Xi Jinping. It has been repeatedly emphasized that to strengthen the construction of ecological civilization, the transformation of economic growth mode must be achieved and the process of building a resource-saving and environment-friendly society must be accelerated. The attention from senior government leaders has greatly increased public awareness and concern about degradation of environmental quality and negative environmental externalities. Thus the lower-level governments and innovation actors had been forced to rethink their functions and behavioral orientation, as well as the business managers and practitioners to rethink the organic combination of social responsibility and development goals of the enterprises. Therefore, it is essential to analyze ecological innovation for guiding the development practice of China's innovation.

At present, there is no unified international definition of ecological innovation in academic circles. Foreign scholars tend to use "environmental innovation" or "green innovation", while domestic scholars usually use "ecological technology innovation". Based on this, this paper adopts the concept of "ecological innovation", which emerged in the 1970s and was first proposed by Fussler and James. James believed that environmental innovation is to bring valuable new products to enterprises while greatly reducing the impact on the environment. However, most foreign scholars follow the definition of environmental innovation as the organization for economic cooperation and development (OECD) proposed, that is, creating new products or technologies to improve the ecological environment intentionally or unintentionally. As for the measurement and indicators, Anthony (2009) had evaluated the performance of ecological innovation from four aspects: input level, knowledge output level, indirect performance level and direct performance level.

Ecological innovation refers to "the production, assimilation or development and production of the product" .As for the organization, it is new process, service, management or business method (Throughout the process of development or the whole life cycle, using this approach can reduce environmental risks, pollution and other negative impacts of resource use (including energy use) compared to related alternatives). Domestic scholars also define this: Based on the basic principles of ecology, green innovation refers to the technological innovation in the production process which not only to promote economic development but also to reduce energy consumption and environmental pollution, with purpose of making the regional economy and the environment harmonious. (Bi Kexin, 2015). In addition, it was also proposed by Caohui(Caohui,2016) that green innovation ability is the integration of "green + innovation + ability". He believed that green innovation ability is the comprehensive ability to transform a certain amount of innovation input into innovation output under the premise of synchronous economic, social and ecological development of a certain region. It can be said that such green innovation ability is the fundamental guarantee of ecological innovation performance. Moreover, some scholars focus on the enterprises when studying eco-innovation performance. They believe that eco-innovation 
performance also has an impact on enterprises, so enterprises' eco-innovation performance needs to consider the utilization of talents, equipment and capital circulation, etc. (Wang Yurong, 2012\& Chen Jin, 2013). However, this paper mainly studies the evaluation of regional eco-innovation efficiency. Therefore, the eco-innovation efficiency adopted in this paper refers to a series of efficiency, including innovation output and environmental output, brought by innovation input within the social scope of the region within a certain period of time.

At present, research on regional innovation ecological performance is mainly based on national, provincial and industrial levels. On the national front, the EU has created the EU Innovation Scoreboard for evaluating national innovation capabilities as well the China Academy of Science and Technology Strategy. Has developed the National Innovation Capacity Evaluation System. At the provincial level, Han Jing (2015) used DEA to measure and analyze green efficiency innovations in 30 provinces and autonomous regions of China; Zhang Yixin (2015) has compared the environmental innovation levels of 30 provinces in China using SBM model; Cao Hui et al. (2016) analyzes and evaluates the green innovation efficiency of 31 provinces, municipalities and autonomous regions in China through collinearity and coefficient of variation methods as well as cluster analysis; based on the combination of DEA and spatial measurement perspectives, Liu Mingguang (2017) evaluated and made a convergence analysis of the green innovation performance of Chinese provinces. In the industry, Bi Kexin et al. (2014) studied the ecological innovation performance of the manufacturing green innovation system. Therefore, the past vast majority of scholars have studied the innovation ecological performance evaluation and the regional level differences from the perspective of inter-provincial comparison, however, this paper is to select the cities in the Yangtze River Delta region as the basic research object in order to be more accurately.

Compared with the traditional innovation performance, the ecological innovation performance is not only the measurement of the economic dimension of innovation, but also the measurement of the ecological environment dimension, that is, whether an innovation activity can reduce energy consumption and reduce environmental pollution. Whether it can promote the improvement of the ecological environment. Therefore, scholars have conducted in-depth research on the evaluation indicators of ecological innovation performance. According to the summary review of Xiao Renqiao (2017), it can be seen that the index system constructed by scholars can be roughly divided into the following three types. First, the input-output perspective is about the performance as an effective output that can be achieved with a certain amount of input. Cheng Hua and Liao Zhongju (2011) built an index system covering five aspects: innovation capital investment, innovation manpower input, environmental regulation input, environmental performance indicators and economic performance indicators; Kong Xiaoni et al. (2015) constructed innovation input indicators and innovation output indicators. Indicator system in four aspects: non-expected output indicators and environmental control indicators; Cao Hui (2016) included green development indicators into the output-output indicator system. Second, from the perspective of innovation process, green innovation is regarded as running through the whole innovation process, that is, green innovation performance is generated in all three stages of the innovation process.Sui jun (2015) constructed evaluation indexes by virtue of three stages: green r\&d performance, green manufacturing performance and green marketing performance.Luo liangwen and liang shengrong (2016) formed evaluation indexes from four aspects of green technology innovation input, intermediate output, expected output and nonexpected output in the two stages of green technology research and development and green technology achievement transformation respectively. Third, economic, social and green parallel (EES), which reflects the most important difference from traditional innovation performance, that is, ecological innovation performance is an efficiency evaluation based on three common dimensions of economic development, social development and ecological development. Bi Kexin (2013) built a full-scale evaluation system with 20 evaluation indicators based on these three criteria. Based on the existing research of scholars, this paper will focus on the basic performance evaluation theory of input-output, under the innovation input of manpower and financial resources, highlight the ecological performance output of the whole process of innovation, and thus carry out the ecology of 26 cities in the Yangtze River Delta. Innovate evaluation and propose corresponding policy recommendations.

\section{Indicator system design and data sources}

\subsection{Evaluation indicator selection}

Technological innovation ability is an important factor of economic growth and social welfare increase, how to evaluate technological innovation ability becomes the key to enhance innovation ability and formulate economic growth policy. To date, many well-known institutions have developed their own indicators and methods for evaluating technological innovations, such as the European Innovation Scoreboard, the World Competitiveness Research Report of the International Management of Lausanne, Switzerland, and the Human Development Report of the United Nations Environment Programme. However, none of the above indicators have taken into account environmental factors.

Based on the multi-input and multi-output DEA model, the assessment of regional eco-innovation efficiency focuses on the rationality of input and output index selection. The analysis of selected input-output indicators plays an important role in the evaluation of eco-innovation efficiency. . In the choice of innovation 
input, it has gone through a single input variable (innovative capital investment or innovative labor input) to consider multiple input factors at the same time. Simply select the flow indicator to consider the time lag effect, and then calculate the inventory indicator of innovation input, but the variable selection of innovation input has been concentrated, mostly innovative capital investment and innovative labor input. According to classical economics, the most basic input factors of economic activities include land, labor and capital. Capital and land are the foundation for $R \& D$ activities. $R \& D$ personnel are the core strength of $R \& D$ activities, while invention patents and new product sales revenues are It is a common indicator of innovation output. This view is an understanding of innovation activities from the perspective of input and output. It can well reflect whether the proportion of input and output in an organization or region is reasonable for a period of time, so as to analyze possible improvement or maintenance strategies. This paper draws on this point of view and believes that the basic investment mainly includes the input of scientific and technical personnel and the investment of science and technology. The scientific and technological output includes the applied for patents, the output value of high-tech industries and the sales income of new products.

To analyze innovative behavior from an ecological perspective, it is necessary to build a more comprehensive indicator system. Different from the traditional innovation efficiency evaluation index system, ecological innovation evaluation should integrate environmental performance, economic performance and social performance, and not only cover general innovation activities. Output also involves energy and the environment. The economic performance here is the final performance in the traditional innovation efficiency evaluation. The ecological innovation performance of this paper covers the measurement of environmental performance and social welfare performance. The regional energy conservation and environmental protection expenditure and the discharge of three wastes are used as indicators, including energy conservation and environmental protection expenditures. Wastewater discharge (10,000 tons), sulfur dioxide emissions (tonnes), soot emissions (tonnes), exhaust emissions (100 million standard cubes), solid waste emissions (10,000 tons).

The above indicators can reflect the economic value and commercialization level of regional innovation achievements, regional independent innovation capability, energy consumption output and environmental pollution status, so as to comprehensively measure the output of regional ecological innovation activities.

\subsection{Data source}

The data are mainly from China statistical yearbook of science and technology, China statistical yearbook and anhui statistical yearbook, covering 16 prefecture-level cities in anhui province, China, from 2012 to 2016 . In the end, the paper obtained the data of eco-innovation performance indicators. Taking 16 prefecture-level cities in Anhui Province of China in 2012-2016 as samples, the regional eco-innovation efficiency and the dynamic comparison of eco-innovation efficiency were compared. Since environmental pollution is an undesired output, and the DEA model used in this paper does not apply to indicators with negative numbers and zeros, the data needs to be processed first. Specifically, the first step is to sum up all the indicators about the environment to get the total amount of environmental pollution in a region; the second step is to select the maximum value of the total number of pollutions, and divide the maximum value by the total number of pollutions in each region. Environmental pollution index. This treatment not only takes into account the characteristics of the DEA model and indicators, but also meets the purpose of this paper.

\subsection{Research methods and analysis}

Since this paper mainly focuses on comparing the innovation efficiency changes of 16 cities in Anhui Province when introducing undesired outputs and not introducing undesired outputs, we adopt the main multi-layer model of the model commonly used in DEA, and the main calculation does not consider the scale return. The efficiency value of the sample under conditions. First assume that there are a total of $\mathrm{n}$ decision units, and each decision unit is the input vector $\mathrm{X}=\left(\mathrm{x} 1, \mathrm{x} 2, \ldots, \mathrm{x}_{\mathrm{m}}\right) \mathrm{T}$, and the output vector $\mathrm{Y}=\left(\mathrm{y} 1, \mathrm{y} 2, \ldots, \mathrm{y}_{\mathrm{s}}\right) \mathrm{T}$, for which Any decision unit DMUj, whose formula is as follows:

$$
\begin{aligned}
& \min \left[\theta-\varepsilon\left(\sum_{i=1}^{m} s_{i}^{-}+\sum_{i=1}^{m} s_{i}^{+}\right)\right] \\
& \operatorname{s.t}\left\{\begin{array}{l}
\sum_{j=j \neq j o}^{n} \lambda_{j} X_{i j}+s_{i}^{-}=\theta x_{0} \\
\sum_{j=1, j \neq j_{o}}^{n} \lambda_{j} Y_{j}-s_{i}^{+}=Y_{\mathrm{O}} \\
s_{r}^{-} \geqslant \mathrm{O} s_{r}^{+} \geqslant \mathrm{O} \\
r_{j} \geqslant \mathrm{O} ; j=1, L, n
\end{array}\right.
\end{aligned}
$$

Where $\theta$ is the effective value of the evaluation decision unit; $\varepsilon$ is the non-Archimedes infinitesimal; is the 
output deficit relaxation variable; is the input residual relaxation variable. Assuming that the optimal solution of the programming problem is $\theta^{*}, \lambda^{*}, *, *$, the following basic conclusion is reached: If $\theta^{*}=1$, the decision unit DMU is weak DEA valid (BCC); if $\theta^{*}=1$, and $*=*=0$, then the decision unit DMU is DEA valid (BCC). If $\theta^{*}<1$, the decision unit is valid for non-DEA.

\section{Data analysis}

In this paper, deap2.1 software is used to calculate the innovation efficiency without the environmental pollution index (as shown in table 1) and the ecological innovation efficiency with the environmental pollution index (as shown in table 2) by using the output oriented constant scale reward multi-stage algorithm.

Table 1 Innovative efficiency without environmental pollution index

\begin{tabular}{|c|c|c|c|c|c|c|c|c|c|c|}
\hline \multirow{2}{*}{$\begin{array}{l}\text { Serial } \\
\text { number }\end{array}$} & \multicolumn{3}{|c|}{ Input slack variable } & \multicolumn{3}{|c|}{ Output slack variable } & \multirow[b]{2}{*}{$\begin{array}{l}\text { Overall } \\
\text { technical } \\
\text { efficiency }\end{array}$} & \multirow{2}{*}{$\begin{array}{l}\text { Technical } \\
\text { efficiency }\end{array}$} & \multirow{2}{*}{$\begin{array}{l}\text { Scale } \\
\text { efficiency }\end{array}$} & \multirow{2}{*}{$\begin{array}{l}\text { Scale } \\
\text { return }\end{array}$} \\
\hline & $\begin{array}{l}\mathrm{R} \& \mathrm{D} \\
\text { person }\end{array}$ & $\begin{array}{l}\text { R\&D } \\
\text { Expenditure }\end{array}$ & $\begin{array}{l}\text { Environmental } \\
\text { spend }\end{array}$ & Paper & Invention & Newprod & & & & \\
\hline Hefei & 0 & 0 & 0 & 28018 & 797867 & 134326 & 0.59 & 1 & 0.59 & drs \\
\hline Huaibei & 0 & 0 & 0 & 0 & 0 & 0 & 1 & 1 & 1 & - \\
\hline Bozhou & 0 & 0 & 0 & 172 & 5797 & 6416 & 0.79 & 1 & 0.79 & irs \\
\hline Suzhou & 250 & 0 & 0 & 328 & 8384 & 8340 & 0.75 & 1 & 0.75 & irs \\
\hline Bengbu & 0 & 287 & 0 & 5022 & 93865 & 48025 & 0.61 & 1 & 0.61 & drs \\
\hline Fuyang & 0 & 0 & 0 & 0 & 0 & 0 & 1 & 1 & 1 & - \\
\hline Huainan & 0 & 0 & 0 & 0 & 0 & 0 & 1 & 1 & 1 & - \\
\hline Chuzhou & 0 & 0 & 0 & 1290 & 37447 & 40229 & 0.45 & 0.88 & 0.51 & drs \\
\hline Luan & 0 & 0 & 0 & 0 & 0 & 0 & 1 & 0.66 & 0.66 & drs \\
\hline Maanshan & 0 & 0 & 0 & 0 & 0 & 0 & 1 & 1 & 1 & - \\
\hline Wuhu & 0 & 0 & 0 & 9003 & 290454 & 60800 & 0.59 & 1 & 0.59 & drs \\
\hline Xuancheng & 0 & 0 & 0 & 0 & 0 & 0 & 1 & 1 & 1 & - \\
\hline Tongling & 0 & 0 & 0 & 0 & 0 & 0 & 1 & 1 & 1 & - \\
\hline Chizhou & 0 & 0 & 0 & 208 & 5024 & 4530 & 0.84 & 1 & 0.84 & irs \\
\hline Anqing & 0 & 0 & 0 & 0 & 0 & 0 & 1 & 1 & 1 & - \\
\hline Huangshan & 0 & 0 & 0 & 0 & 0 & 0 & 1 & 1 & 1 & - \\
\hline
\end{tabular}

NOTE: IRS=Increasing Returns to Scale; DRS=Decreasing Returns to Scale

Table 2 Innovative efficiency including environmental pollution index

\begin{tabular}{|c|c|c|c|c|c|c|c|c|c|c|c|}
\hline \multirow{2}{*}{$\begin{array}{c}\text { Serial } \\
\text { number }\end{array}$} & \multicolumn{3}{|c|}{ Input slack variable } & \multicolumn{4}{|c|}{ Output slack variable } & \multirow{2}{*}{$\begin{array}{l}\text { Overall } \\
\text { technical } \\
\text { efficiency }\end{array}$} & \multirow{2}{*}{$\begin{array}{l}\text { Technical } \\
\text { efficiency }\end{array}$} & \multirow{2}{*}{$\begin{array}{c}\text { Scale } \\
\text { efficiency }\end{array}$} & \multirow{2}{*}{$\begin{array}{l}\text { Scale } \\
\text { return }\end{array}$} \\
\hline & $\begin{array}{l}\text { R\&D } \\
\text { person }\end{array}$ & $\begin{array}{l}\mathrm{R} \& \mathrm{D} \\
\text { Expenditure }\end{array}$ & ES & Paper & Invention & Newprod & EI & & & & \\
\hline Hefei & 0 & 0 & 0 & 0 & 0 & 0 & 0 & 1 & 1 & 1 & - \\
\hline Huaibei & 0 & 0 & 0 & 0 & 0 & 0 & 0 & 1 & 1 & 1 & - \\
\hline Bozhou & 0 & 0 & 0 & 0 & 0 & 0 & 0 & 1 & 1 & 1 & - \\
\hline Suzhou & 0 & 0 & 0 & 0 & 0 & 0 & 0 & 1 & 1 & 1 & - \\
\hline Bengbu & 0 & 0 & 0 & 0 & 0 & 0 & 0 & 1 & 1 & 1 & - \\
\hline Fuyang & 351 & & & 67 & 5 & 40815 & 0 & 0.94 & 0.95 & 0.988 & Irs \\
\hline Huainan & 0 & 0 & 0 & 0 & 0 & 0 & 0 & 1 & 1 & 1 & - \\
\hline Chuzhou & 0 & 0 & 0 & 0 & 0 & 0 & 0 & 1 & 1 & 1 & - \\
\hline Luan & 0 & 0 & 0 & 0 & 0 & 0 & 0 & 1 & 1 & 1 & - \\
\hline Maanshan & & 53504 & 0 & 505 & 165 & 762141 & & 0.78 & 0.81 & 0.96 & irs \\
\hline Wuhu & 0 & 0 & 0 & 0 & 0 & 0 & 0 & 1 & 1 & 1 & - \\
\hline Xuancheng & 0 & 0 & 6349 & 135 & 212 & 774930 & 2 & 0.55 & 0.55 & 0.99 & irs \\
\hline Tongling & 0 & 0 & 0 & 0 & 0 & 0 & 0 & 1 & 1 & 1 & - \\
\hline Chizhou & 0 & 0 & 0 & 0 & 0 & 0 & 0 & 1 & 1 & 1 & - \\
\hline Anqing & 982 & 0 & 0 & 305 & 41 & 292433 & 0 & 0.79 & 0.79 & 0.99 & - \\
\hline Huangshan & 0 & 0 & 0 & 0 & 0 & 0 & 0 & 1 & 1 & 1 & - \\
\hline
\end{tabular}

Note: $\mathrm{EI}=$ Environmental index; $\mathrm{ES}=$ Environmental spend

\section{Result}

According to the analysis of Anhui Li Yi's innovation ability in Anhui Province, the analysis of the technology input capacity, technical support capacity and technology output capacity utilization factor analysis method of Anhui provinces and cities shows that Hefei scores 2.81 points and Wuhu 0.74 points. The score is 0.01 , and the other provinces are all below 0 (here below 0 is relative, measuring the difference, not the absolute number). We can see that Hefei, as the provincial capital, is in a dominant state in terms of science and technology investment, physical infrastructure and information infrastructure. The innovation ability is 3.8 times that of the second place Wuhu. Besides Tongling and Ma'anshan, which maintain weak advantages by relying on traditional industries, other cities still rely on factor investment to drive economic development, which is not matched with China's big strategic development direction.

Of course, the above analysis is an absolute analysis of innovation capabilities and does not take into 
account the efficiency of input and output. According to Table 1, we can find that only the innovation input and output of nine urban areas such as Huaibei, Xiangyang, Huainan, Lu'an, Ma'anshan and Xuancheng are relatively effective. The comprehensive technical efficiency of Hefei is only 0.59 , and it is in the stage of decreasing scale efficiency. It proves that under the same input conditions, the output of Hefei paper needs to increase by 28018 , the patent needs to increase by 797867 , and the output value of new products needs to increase by 134326, which can be called effective. Input and output, which is different from the above traditional efficiency evaluation results. Similarly, Bengbu, Chuzhou and Wuhu belong to the same situation as Hefei. The main reason for this phenomenon is that Anhui Province regards the construction of the Hefei National Independent Innovation Demonstration Zone as a system to promote the comprehensive innovation reform experiment, with various innovation platforms as the important carriers to promote the combination of high-end scientific and technological talents and mass entrepreneurship innovation. For the new mission, accelerate the construction of four innovation systems of technology and industry, finance and capital, platform and enterprise, system and policy, and increase investment in innovation in Hefei, Wuhu and Anhui, but for a long time, it has been affected by the centralized science and technology management system. The problems of scattered, closed and lack of integration of innovative resources in Hefei, Wuhu and Anhui led to the inefficiency of the entire innovation system. The interactions and connections between the innovation subjects are not close enough, and there are a large number of isolated islands of innovation, which in turn affects the efficiency of innovation. For Zhangzhou, Suzhou and Chizhou, in the stage of increasing returns to scale, it is still possible to formulate a reasonable innovation system and improve resource utilization efficiency by increasing innovation investment or rationally planning the relationship between innovation entities.

According to Table 2, when the environmental index is added, the input and output efficiency of Hefei is improved and it is an effective unit of DEA. In other regions, only Xiangyang, Maanshan, Xuancheng and Anqing are not effective units, but in the stage of increasing returns to scale, it means that these four regions can increase investment and achieve innovation performance and environmental performance improvement.

\section{Policy implications}

The uneven development of the regions in Anhui Province is an economic problem that has been difficult to solve all the time. In the process of promoting innovation and development, this imbalance is once again amplified. This is mainly because on the one hand, the resources owned by different regions are different; on the other hand, the industrial structure of different regions is different, and the demand for technological innovation is also different, resulting in differences in innovation capabilities between regions. The level of innovation ability has a certain impact on the wealth creation ability of the region. Therefore, the low investment in innovation will inevitably lead to higher innovation output, which will naturally hinder the local economic development, and thus will fall into a vicious cycle. Therefore, when formulating policies, we need to consider the overall efficiency of the green innovation chain and open up the innovation chain, capital chain and transformation chain. Specifically, it is mainly divided into the following points:

(1) Encourage qualified regions to establish intellectual property insurance rewards and subsidies, accelerate the development of intellectual property insurance, and encourage innovation in patent insurance products. Actively promote the work of intellectual property rights overseas infringement liability insurance. We will carry out trials of risk compensation funds for financing pledged by intellectual property rights and intellectual property operating funds for key industries. Innovative investment and financing products. We will explore the securitization of intellectual property rights, improve the credit guarantee mechanism for intellectual property rights, and promote the development of new models such as linked lending, insurance, and bond investment. Actively develop services such as intellectual property pledge financing, credit insurance policy financing and credit, encourage the development of "Internet" through bond financing, and support qualified "Internet" companies to issue corporate bonds. In the comprehensive innovation reform pilot area, cultivate angel investors, guide venture capital funds, and equity investment funds to strengthen investment in high-tech fields.

(2) Encourage model innovation, encourage crowd funding platform specialization, investment localization, and entrepreneurial enterprise participation to explore development in multiple directions; encourage innovation and entrepreneurship, strengthen cooperation between industry, university and research institutes of various types of entrepreneurial service platforms, promote technological innovation, and revitalize Applied technology; With the trend of Hefei comprehensive national science center, create a globally influential entrepreneurial center, further improve the ecological environment for entrepreneurial incubation; encourage angel investment, establish preferential investment system for angel investment through personal income tax credit policy, and promote angel investment clubs and industries. Organizations and other organizations develop; promote financial system reform, introduce policies to guide the development of public fundraising platforms, promote information sharing and sharing, and optimize the credit environment.

(3) Actively develop ecological innovation, advocate the development path of green innovation with high 
efficiency and environmental protection, realize the coordinated development of environment and science and technology, and promote the improvement of economic level. First, reform the performance appraisal system of government officials in some areas of Anhui, combine environmental performance with economic and technological development, and measure the performance of regional officials. Secondly, due consideration can be given to the collection of environmental taxes and the establishment of regionally differentiated environmental tax rates. Finally, based on the theory of social responsibility, cultivate the consciousness and ability of enterprise ecological innovation, and promote the gradual transformation of enterprises from passive recipients of environmental regulation to active participants in environmental regulation.

\section{References}

[1] Fussler, C.\& P. James. Driving Eco-innovation A Breakthrough Discipline for Innovation and Sustainability [M]. Financial Times/Prentice Hall, 1997.

[2] Jun, S., Xin, B. K., Jun, Y. C., \& Gang, L. (2015). Research on the factors of innovation performance of manufacturing green innovation system: From the perspective of MNCs' technology transfer [J]. Studies in Science of Science, 33(3), 440-448.

[3] Cao, H., Shi, B.F. , \& Zhao, K., (2016). Evaluation on Provincial Green Innovation Capability in China. Chinese Journal of Management, 13(8), 1215-1222.

[4] Jin, C. H. E. N., Liang, L. I. A. N. G., \& Hang, W. U. (2013). Industrial agglomeration and innovation performance under the background of open innovation: evidence from chinese high-tech industries [J]. Studies in Science of Science, 31(4), 623-629.

[5] Han, J., Wang, Y., \& Chen, C.F, (2015). A Study on Regional Differences of Industrial Carbon Emissions Performance and Its Factors in China Spatial Econometric Analysis Based on Provincial Data. Comparative Economic \& Social Systems (1).113-122

[6] Zhang, Y.X., Ling, X.M., (2015). Dual Evolution of Green Innovation Efficiency and System Coordination Degree in China's Provinces. Contemporary economic research (3), 51-56.

[7] Liu,M.G., (2017). Dynamic Evaluation of Innovation Efficiency of Guangdong Regional Innovation System Based on Dea-malmquist Index Method. Statistics and Management (1), 67-71.

[8] Bi,K.X.,(2014). Effect of Innovation Resources Input on Green Innovation Capability of Green Innovation System: Empirical Research from the Perspective of Manufacturing FDI Inflows. Chinese Soft Science (3), 153-166.

[9] Xiao, R.Q., \& Ding, J., (2017). Research on the Green Innovation Efficiency and Spatial Spillover Effects in Chinese Enterprises. Journal of Shanxi University of Finance and Economics, 39(12), 45-58.

[10] Cheng, H., \& Liao, Z.J., (2011). China regional environmental innovation performance evaluation and research. Chinese Environmental Science, 31(3), 522-528.

[11] Kong, X.N., \& Deng, F., (2015). The Evaluation of the Green Innovation Efficiency and the Path to Improvement in China - An Influencing Factor- Based Analysis. Journal of Xinjiang University, 43(4), 14-18.

[12] Luo, L.W., \& Liang, S.R., (2016). Industrial Agglomeration, Economic Globalization and the Regional Imbalance of Urbanization in China: An Empirical Study Based on Provincial Panel Data. International Economics and Trade Research, 32(6), 48-57.

[13] Li, W.H., Bi, K.X, \& Sun, B., (2013). Research on the Effect of Environmental Regulation Intensity on Green Technological Innovation of Pollution Intensive Industries__Empirical Test Based on Panel Data of 2003-2010. R \& D Management, 25(6), 72-81 